\title{
Simulation Research of the Influence of Compression Ratio on the Performance of an Aircraft Piston Diesel Engine
}

\author{
Łukasz Grabowski', Paweł Karpiński ${ }^{* *}$, Paweł Magryta ${ }^{1}$ \\ 1 Lublin University of Technology, Faculty of Mechanical Engineering, Department of Thermodynamics, Fluid \\ Mechanics and Aviation Propulsion Systems; ul. Nadbystrzycka 36, 20-618 Lublin, Poland \\ * Corresponding author's e-mail: pawel.karpinski@pollub.edu.pl
}

\begin{abstract}
In recent years, the opposed-piston engines have become increasingly popular in the automotive and aerospace industries. Therefore, it is necessary to conduct the research on this type of drive. The paper presents the simulation research of a two-stroke opposed-piston diesel engine designed for propulsion of light aircrafts. The influence of the change of the compression ratio on the selected engine performance was investigated (indicated mean effective pressure, peak firing temperature and pressure, specific fuel consumption, power consumed by the compressor). The AVL BOOST software was used to perform the simulation tests. A zero-dimensional engine model equipped with a mechanical compressor was developed. On the basis of the created model, a series of calculations was performed for the assumed values of the compression ratio for four engine operating points: take-off power, maximum continuous power and cruising power at two different altitudes. The obtained results were subjected to a comparative analysis and the most important conclusions connected with the influence of the change in the compression ratio on the achieved performance were presented.
\end{abstract}

Keywords: aircraft, compression ratio, diesel engine, opposed-piston, two-stroke.

\section{INTRODUCTION}

With the beginning of the 21 st century, in the automotive industry there has been a trend of replacing the internal combustion engines with the electric or hybrid engines. This trend is mainly due to the care for the natural environment and human health. Additionally, in other areas of transport, e.g. in aviation, there are more and more studies and development projects aimed at optimizing the design of aircraft propulsion systems $[24,12]$. The basic goal currently set by the constructors is to reduce the fuel consumption and the emission of toxic substances. One of the ways to significantly reduce the emission by aircraft propulsion is to change the design of a propulsion unit. In light aircraft and unmanned ships, a small piston engine is usually used as the main source of propulsion. The paper [11] presents the research on such engines. However, an interesting solution seems to be the use of an innovative construction of a diesel engine with opposed pistons for propelling this type of aircraft. The strength of a piston of this type of engine was analyzed in paper [19]. The general possibility of using the opposed piston engines in the future was presented in work [27]. Some papers focused on the development of the opposed piston engines [21, 18, 31]. There are also works in which the charge exchange system was studied $[8,10]$, or the effect of injection on the operation of this type of engine was analyzed [32].

Another issue is the fact that currently, the automotive industry is showing a trend of abandoning the production of diesel engines, but their use in aviation is becoming more and more popular due to the advances in materials engineering that enabled the use of modern materials to reduce the mass of these engines. Similarly, it seems possible to use in aviation the modern high-pressure injection Common Rail technology, which has been dynamically developed since the early 1990s, as described in work [30]. Such aspects confirm that of using diesel engines in light aviation is 
purposeful. The possibility of supplying a Diesel engine with the kerosene is investigated $[23,6]$.

In order to make use of any new drive possible, it must go a long way, starting with the concept, through the design, to its mass production. This second step seems to be easier to do now than many years ago, owing to the possibility of using computer aided design and calculation. Currently, at the stage of engine design, after the assumption of its main technical parameters, it is possible to simulate its efficiency and processes, including combustion process, charge exchange, etc. under different operating conditions.

The computer aided design in the case of internal combustion engines is widely used by manufacturers. There are many works focusing on this subject. The general design process was described in paper [22]. The CFD models were presented in the works $[28,26,3,17]$. The 1D models were also analyzed [25, 9]. All works proved that it is appropriate to use modeling for the design of drive units.

The authors of this publication also employed this method, using the AVL Boost program, which is applied to model and simulate the work of piston engines.

One of the aspects to be taken into account during the design work is the compression ratio, which was proven in work [2]. The value of this parameter in the last 20-30 years has been reduced in diesel engines. The impact of the change of compression ratio on the engine performance, its combustion process and emission of toxic substances was described in works $[4,16,1]$. There are also works focusing on the operation of an alternative fueled engine $[14,5]$.

It was possible owing to the introduction of high-pressure fuel systems (smaller drops, better atomization, possible self-ignition). The influence of the CR parameter on the engine performance was studied in works $[15,20,29,13]$, where the significance of the compression ratio influence on the performance of the engine was proved.

This paper attempts to determine how changing the compression ratio affects the performance of an opposed-piston diesel engine. The research engine is in the design phase and is intended to be used in light aircraft and unmanned aerial vehicles. The basic technical parameters of the test object are presented in Table 1.

The purpose of the research conducted in this work was the analysis of the selected parameters of the two-stroke opposed-piston aircraft diesel
Table 1. Basic parameters of the research engine

\begin{tabular}{|c|c|}
\hline Type & $\begin{array}{c}\text { Compression-ignition engine } \\
\text { with opposed pistons }\end{array}$ \\
\hline Number of strokes & 2 \\
\hline Number of cylinders & 3 \\
\hline Cylinder stroke & $71.5 \mathrm{~mm}$ \\
\hline Cylinder bore & $92.6 \mathrm{~mm}$ \\
\hline Maximum power & $100 \mathrm{~kW}$ \\
\hline Engine speed & $4200 \mathrm{rpm}$ \\
\hline Scavenging type & Uniflow with mechanical compressor \\
\hline
\end{tabular}

engine depending on the compression ratio. The obtained results will enable the optimization of the engine design and will show what effect the compression ratio has on the performance of the research engine. Further work on the engine will allow the validation of the developed engine model.

\section{ENGINE MODEL}

The AVL BOOST software was used to analyze the impact of the compression ratio on the performance of the research engine. In this program, a zero-dimensional engine model was created, which was connected by a shaft to a mechanical compressor (Fig. 1). The model was created using block elements that characterized the work of specific engine components (TCP1 mechanical compressor, $\mathrm{CO} 1$ intercooler, $\mathrm{C} 1-\mathrm{C} 3$ engine cylinders as well as intake and outlet lines marked with numbers). The defined MP measurement points enabled flow parameters monitoring.

The zero-dimensional model of the engine is characterized by the fact that the thermodynamic parameters are calculated as average parameters

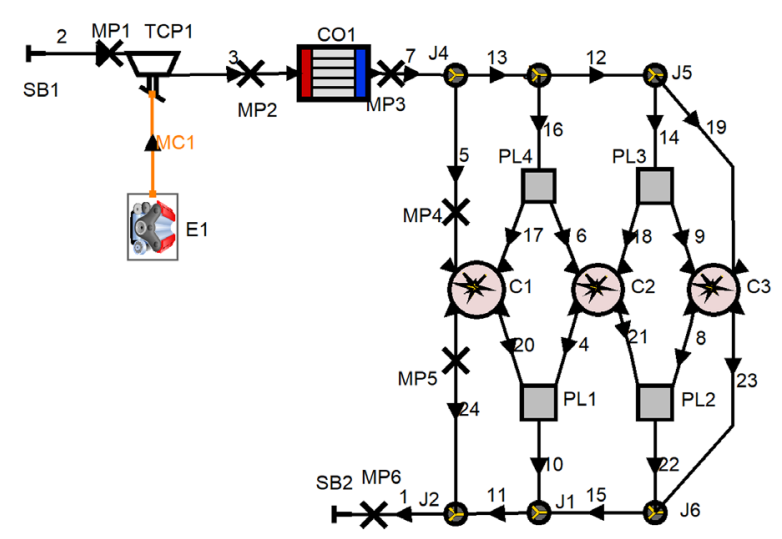

Fig. 1. The research engine model created in the AVL BOOST software 


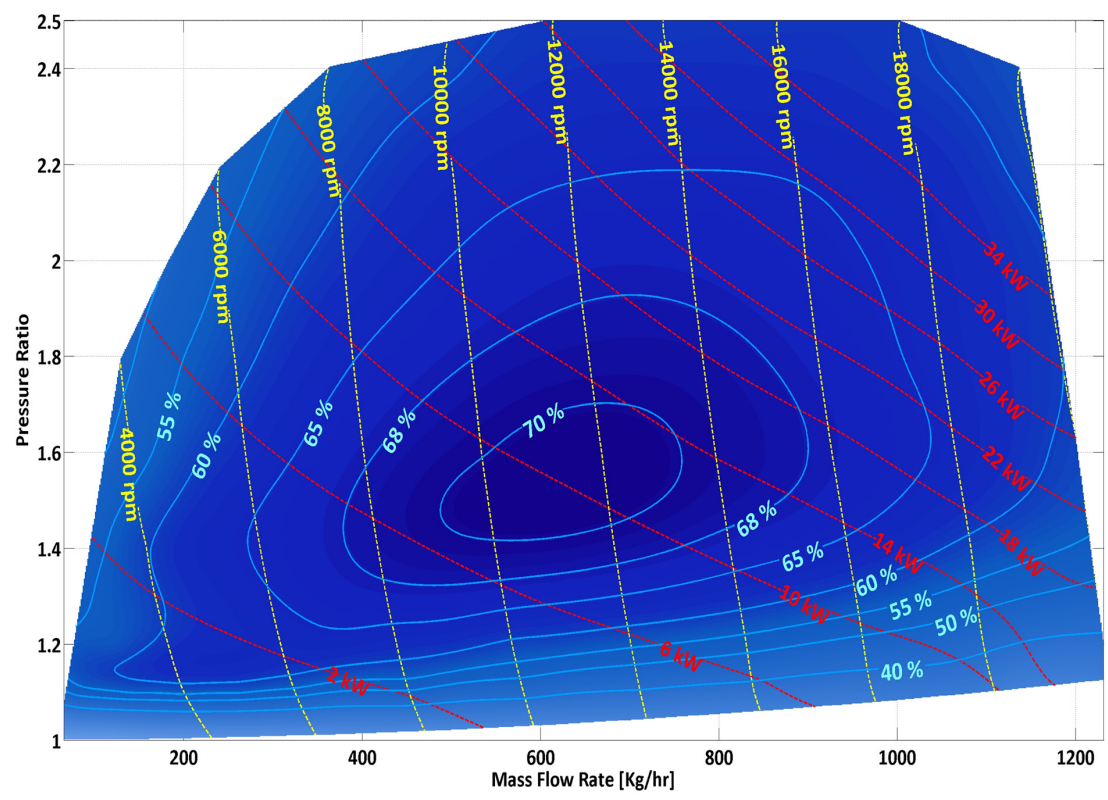

Fig. 2. Map of the Eaton TVS R900 compressor used in the research engine model [7]

inside the combustion chamber, and the flame formation process is not taken into account. The key variable describing the changes taking place in the model is the time parameter. The flow through the ducts is modeled as one-dimensional, which means that the average flow values are calculated for a given channel cross section. All the actually occurring flow losses are replaced by the corresponding flow coefficients.

In the case of a two-stroke opposed-piston engine with uniflow scavenging, the improvement of the charge exchange process is achieved by applying a phase shift between the engine shafts. This shift should occur between the shaft on the side of the inlet ports and the shaft on the side of the outlet ports. This phase shift is called an offset. For the engine tested, the assumed phase change was 14 degrees. The parameters characterizing the charge exchange process are defined in the cylinder settings by

Table 2. Engine operating points characterized by power, engine speed and air to fuel ratio $(A F R)$

\begin{tabular}{|c|c|c|c|}
\hline Operating point & $\begin{array}{c}\text { Power } \\
(\mathbf{k W})\end{array}$ & $\begin{array}{c}\text { Engine } \\
\text { speed (rpm) }\end{array}$ & $\begin{array}{c}\text { AFR } \\
(-)\end{array}$ \\
\hline Take-off power & 100 & 4200 & 21.5 \\
\hline $\begin{array}{c}\text { Maximum continu- } \\
\text { ous power }\end{array}$ & 86 & 4000 & 24 \\
\hline $\begin{array}{c}\text { Cruising power } \\
\text { at altitude H=0 m }\end{array}$ & 73 & 3800 & 26.5 \\
\hline $\begin{array}{c}\text { Cruising power } \\
\text { at altitude } H=2300 \mathrm{~m}\end{array}$ & 73 & 3800 & 21.5 \\
\hline
\end{tabular}

entering the inlet and outlet ports opening times and their effective flow areas.

The map of the Eaton TVS R900 mechanical compressor (Fig. 2) was introduced into the engine model and the gear ratio between the engine shaft and the compressor shaft was defined. Its value was set to $1: 2.91$.

The model defined by the Viebe function was adopted as the combustion model. It uses four parameters to determine the rate of heat release (ROHR) and mass fraction burned (MFB). These parameters are: start of combustion $(\mathrm{SoC})$, combustion duration, shape parameter $m$ and additional parameter $a$.

The Woschni 1978 model was adopted as a heat exchange model. It is based on defining the temperature of selected surfaces on the engine components such as a cylinder head or a piston.

The operating points used to perform the simulation tests are shown in Table 2. For each of the work points, a series of tests was conducted, differing in the compression ratio $\varepsilon$. The engine power for a given calculation point was adjusted by changing the start of combustion angle SoC (Table 3).

The compression ratio values for which the calculations were performed, were as follows: $16,17,18,19,20,21,22$. For the defined operating points, the values of the indicated mean effective pressure $I M E P$, peak firing temperature $T_{\max }$ and peak firing pressure $p_{\max }$, break specific fuel consumption $B S F C$ and compressor power $N_{c}$ were analyzed. 
Table 3. The start of combustion ( $S O C$ ) values expressed in deg for the considered operating points determined by the power and compression ratio $\varepsilon$

\begin{tabular}{|c|c|c|c|c|}
\hline $\boldsymbol{\varepsilon}(-)$ & Take-off power & Maximum continuous power & Cruising power at $\mathbf{H}=\mathbf{0} \mathbf{~ m}$ & Cruising power at $\mathbf{H}=\mathbf{2 3 0 0} \mathbf{~}$ \\
\hline 16 & -4.0 & -4.0 & -2.0 & -4.0 \\
\hline 17 & -3.0 & -3.0 & -2.0 & -4.0 \\
\hline 18 & -2.0 & -1.5 & -1.5 & -3.5 \\
\hline 19 & -1.5 & -1.0 & -1.0 & -3.0 \\
\hline 20 & -0.5 & -0.5 & -1.0 & -1.5 \\
\hline 21 & 1.0 & 0.0 & 0.0 & 0.5 \\
\hline 22 & 1.5 & 0.0 & 0.0 & 1.0 \\
\hline
\end{tabular}

\section{SIMULATION RESULTS AND DISCUSSION}

The figures shown in the following present the results of calculations for the analyzed values of the compression ratio. The indicated mean effective pressure, peak firing pressure and temperature, break specific fuel consumption and compressor power were presented. Figure 3 shows the indicated mean effective pressure for analyzed work points for selected values of the compression ratio. It can be seen that the obtained IMEP values are similar and do not differ by more than $0.01 \mathrm{MPa}$. This is due to the fact that in each case, the engine power was maintained at a constant value and it was obtained by modifying the $\mathrm{SoC}$ values. The value of the IMEP for the analyzed engine work points slightly increases along with the value of the compression ratio. The results obtained show that a change in the compression ratio does not necessarily have a significant impact on the IMEP. This is because the start of combustion was modified during the experiment. This affected the course of the modeled working process of the engine, and in particular the heat development process in the cylinder. It should also be noted that for all variants of power output

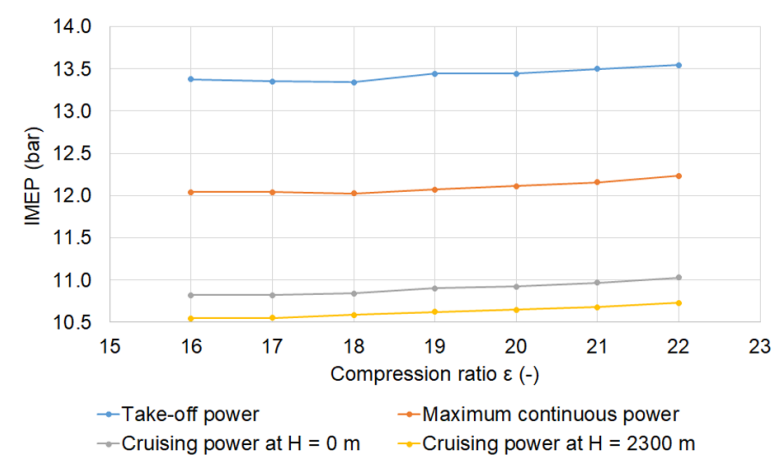

Fig. 3. Indicated mean effective pressure in relationship to the compression ratio for defined operating points (take-off power, maximum continuous power, etc.) the trend of changes is similar.

Referring to the peak firing temperature (Fig. 4), it can be seen that increasing the CR causes a decrease in the value of this parameter. This is noticeable for each power value. This drop is over $160 \mathrm{~K}$ for take-off power. Such changes in the value resulted from the necessity to change the SoC parameter in order to maintain constant power values. In all cases, increasing the compression ratio caused the need to delay the start of combustion.

While analyzing this parameter, it should be noted that the change is from about $1.7 \%$ for minimum power i.e. cruising power and $3.6 \%$ for maximum power i.e. take-off power. For each power value, it can be concluded that an appropriate construction of the combustion chamber (compression ratio) and organization during the combustion process (start of combustion, start of injection) can reduce the heat load of the engine combustion chamber.

The delay at the beginning of the combustion process shifted this process to the work stroke. At the same time, an increase of the compression ratio resulted in a raise of the maximum pressure

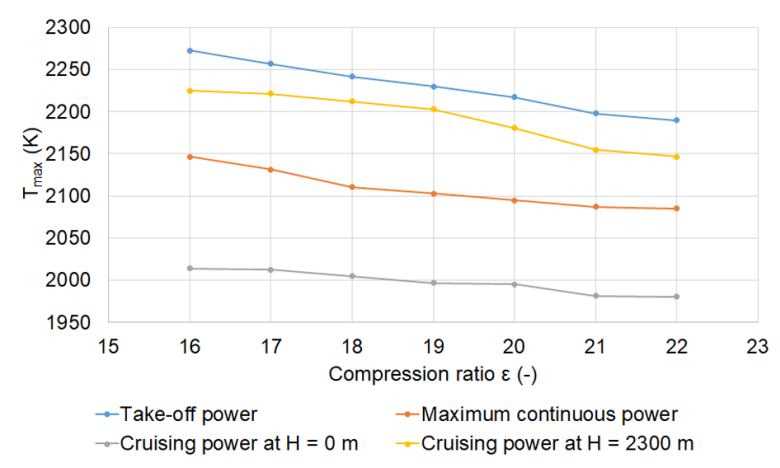

Fig. 4. Peak firing temperature in relationship to the compression ratio for defined operating points 


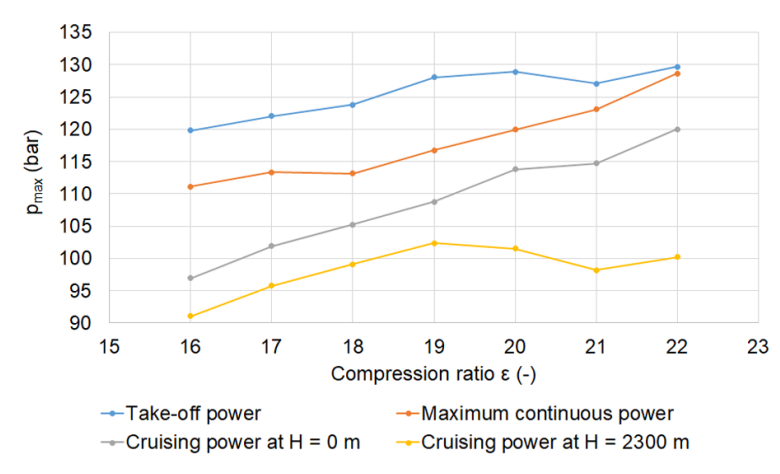

Fig. 5. Peak firing pressure in relationship to the compression ratio for defined operating points

in the cylinder. Only in the case of cruising power at $2300 \mathrm{~m}$ there is a maximum for $\mathrm{CR}$ equal to 19 . In other cases, there is an upward trend. For the extreme CR values, the differences are around $1 \mathrm{MPa}$. It should be emphasized that in this case, the main factor that causes the increase in the maximum pressure is the increased value of the compression ratio. The increase in the value for $\mathrm{CR}=19$ for the take-off power and cruising power at $2300 \mathrm{~m}$ can be caused by the efficiency of the compressor.

The maximum pressure value was obtained for the take-off power and CR $=22$ (Fig. 5). The obtained peak pressure values were reduced in the case of increasing the compression ratio by delaying the start of combustion. It should be noted that for the maximum compression ratio values, the combustion begins after TDC, which is unfavorable due to the efficiency of the work cycle.

As with the previous parameters, the changes in the maximum pressure in the cylinder also confirmed the effect of compression ratio. For each power variant, an average increase in the

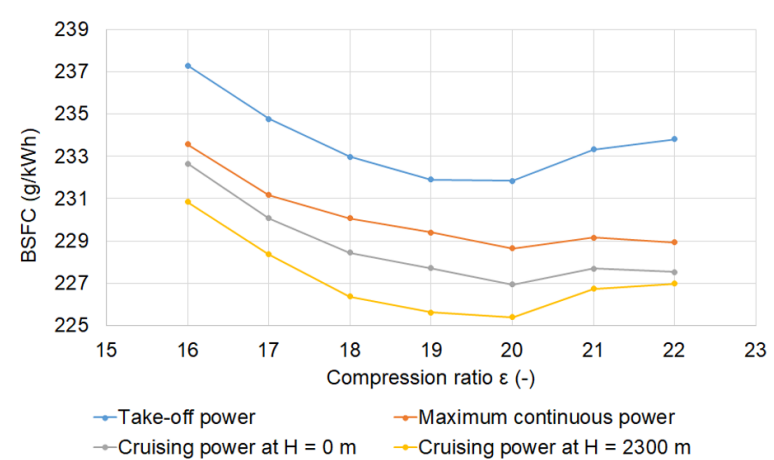

Fig. 6. Break specific fuel consumption in relationship to the compression ratio for defined operating points maximum pressure in the cylinder of about $1.6 \%$ was obtained. It can be concluded that the mechanical load will increase along with the compression ratio. This is particularly important for relieving the bearings, piston pin, connecting rod and crankshaft. Therefore, when changing the $\mathrm{CR}$, one should definitely take into account the strength of the above mentioned engine parts.

This is evident from Figure 6, which presents $\mathrm{BSFC}$ in relationship to the $\mathrm{CR}$ for subsequent operating points. It can be conclusively stated that the minimum break specific fuel consumption is observed for each operating point at $\mathrm{CR}=20$. However, the differences between the maximal and minimal values are not large and are equal to $5-6 \mathrm{~g} / \mathrm{kWh}$. It can also be concluded that the setting of start of combustion also has an additional effect on the minimum BSFC value. The differences obtained are no more than $2 \%$. Therefore, it can be concluded that the effect of the compression ratio combined with a change in the start of combustion does not significantly affect the overall efficiency of the engine. However, due to its minimum value it is worth considering the impact of the compression ratio on the BSFC value during the engine design.

Referring to Figure 7, the lowest power consumed by a mechanical compressor was obtained for $\mathrm{CR}=20$ for all work points considered. For a given work point, the power does not change by more than $1 \mathrm{~kW}$ for the analyzed range of compression ratio. It is due to the fact that the highest compressor efficiency occurred for this point. This is also related to the conditions prevailing in the cylinder (pressure) to which the compressor supplied the air. It should be emphasized that in the case of the two-stroke diesel engine, the compression ratio modification changes the operating

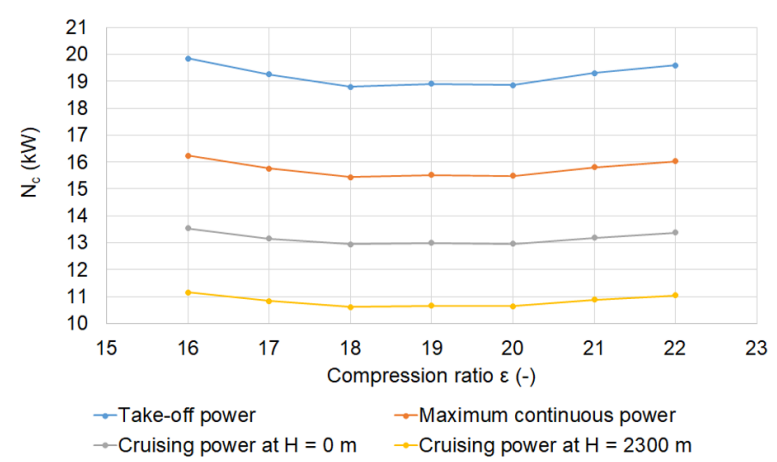

Fig. 7. Compressor power in relationship to the compression ratio for defined operating points 
conditions of the supercharging compressor. For CR equal to 18 and 19 , the value of power consumed by the compressor is close to the power corresponding to $\mathrm{CR}=20$.

Despite small changes in the power consumed by the mechanical compressor, they are in the range of 3 to $4 \%$. The obtained minimum power value also occurs for $\mathrm{CR}=20$, which is reflected in the $\mathrm{BSFC}$ value for $\mathrm{CR}=20$. It can therefore be assumed that a compression ratio of 20 is optimal in terms of energy, i.e. for all operating conditions (take-off power, maximum continuous power, etc.) there is a minimum fuel consumption.

\section{CONCLUSIONS}

As a result of the simulation tests performed on the created engine model, the way how the compression ratio influences the selected engine parameters in the two-stroke opposed-piston diesel engine was analyzed. The tests were conducted for four characteristic work points of the engine.

The greatest impact of the compression ratio occurred in the case of break specific fuel consumption. The minimum BSFC values were obtained for CRs equal to 18, 19 and 20. Further increase or decrease of the analyzed parameter value results in an increase in break specific fuel consumption.

In addition, it was observed that the BSFC value is correlated with the compressor power, because also the minimum in the plot is present for this parameter. It should be noted that the obtained curves for compressor power are flatter compared to the curves for BSFC.

The value of IMEP for a given work point remained relatively constant due to the assumption made to maintain constant engine power. Peak firing pressure increased along with the compression ratio, while in the case of peak firing temperature there was a downward trend. Due to the assumption of maintaining a constant power for a given working point, the pressure increase was compensated by a drop in temperature. In this way, the amount of energy released in the process was the same.

Further work on the model will focus on its validation based on bench tests. It will then be possible to perform an extended analysis of the impact of the compression ratio on the selected operating parameters of the research engine.

\section{Acknowledgements}

This work has been realized in the cooperation with The Construction Office of WSK "PZL-KALISZ" S.A. and is part of Grant Agreement No. POIR.01.02.00-00-0002/15 financed by the Polish National Centre for Research and Development.

\section{REFERENCES}

1. Adnan P., Halit Y., Bahri S. Performance and exhaust emission characteristics of a lower compression ratio LHR Diesel engine. Energy Conversion and Management, 44, 2003, 163-175.

2. Alqahtani A., Wyszynski M.L., Mazuro P., Xu H. Evaluation of the effect of variable compression ratios performance on opposed piston 2-stroke engine. Combustion Engines, 56(4), 2017, 97-106. DOI: 10.19206/CE-2017-417.

3. Asadi A., Zhang Y., Mohammadi H., Khorand H., Rui Z., Doranehgard M.H., Bozorg M.V. Combustion and emission characteristics of biomass derived biofuel, premixed in a diesel engine: A CFD study. Renewable Energy, 138, 2019, 79-89. DOI: 10.1016/j.renene.2019.01.069.

4. Bhaskor J.B., Ujjwal K.S., Soumya C., Vijay V. Effect of compression ratio on performance, combustion and emission characteristics of a dual fuel diesel engine run on raw biogas. Energy Conversion and Management, 87, 2014, 1000-1009. DOI: 10.1016/j.enconman.2014.07.080.

5. Laguitton O., Crua B., Cowell T., Heikal M.R., Gold M.R. The effect of compression ratio on exhaust emissions from a PCCI diesel engine. Energy Conversion and Management, 48, 2007, 2918-2924. DOI: 10.1016/j.enconman.2007.07.016.

6. Cenk S., Metin G. Impact of compression ratio and injection parameters on the performance and emissions of a DI diesel engine fueled with biodieselblended diesel fuel. Applied Thermal Engineering, 31, 2011, 3182-3188. DOI: 10.1016/j.applthermaleng.2011.05.044.

7. Chen L., Ding S., Liu H., Lu Y., Li Y., Roskilly A. P. Comparative study of combustion and emissions of kerosene (RP-3), kerosene-pentanol blends and diesel in a compression ignition engine. Applied Energy, 203, 2017, 91-100. DOI: 10.1016/j.apenergy.2017.06.036.

8. Compressor Eaton TVS-R900 Specification https:// www.eaton.com/us/en-us/catalog/engine-solutions/tvs-r900.specifications.html.

9. Czyz Z. Siadkowska K., Sochaczewski R. CFD Analysis of Charge Exchange in an Aircraft Op- 
posed-Piston Diesel Engine. MATEC Web of Conferences, 252, 2018, 04002. DOI: 10.1051/matecconf/201925204002.

10. D’Errico G., Cerri T., Pertusi G. Multi-objective optimization of internal combustion engine by means of 1D fluid-dynamic models. Applied Energy, 88(3), 2011, 767-777. DOI: 10.1016/j.apenergy.2010.09.001.

11. Grabowski L., Pietrykowski K., Karpiński P. Charging process analysis of an opposed-piston two-stroke aircraft Diesel engine. ITM Web of Conferences, 15, 2017, 03002. DOI: 10.1051/itmconf/20171503002.

12. Grabowski Ł., Siadkowska K., Skiba K. Simulation Research of Aircraft Piston Engine Rotax 912. MATEC Web of Conferences, 252, 2019, 05007. DOI: $10.1051 /$ matecconf $/ 201925205007$.

13. Magryta P., Gęca M. FEM analysis of piston for aircraft two stroke diesel engine. MATEC Web of Conferences, 252, 2018, 07004. DOI: 10.1051/ matecconf/201925207004.

14. Jakovljević I., Mijailović R., Mirosavljević P. Carbon dioxide emission during the life cycle of turbofan aircraft. Energy 148, 2018, 866-875. DOI: 10.1016/j.energy.2018.02.022.

15. Jiaqiang E. Pham M. H., Deng Y., Nguyen T., Duy V. N., Le D. C., Zuo W., Peng Q., Zhang Z. Effects of injection timing and injection pressure on performance and exhaust emissions of a common rail diesel engine fueled by various concentrations of fish-oil biodiesel blends. Energy, 149, 2018, 979989. DOI: 10.1016/j.energy.2018.02.053.

16. Jindal S., Nandwana B.P., Rathore N.S., Vashistha V. Experimental investigation of the effect of compression ratio and injection pressure in a direct injection diesel engine running on Jatropha methyl ester. Applied Thermal Engineering, 30, 2010, 442-448. DOI: 10.1016/j.applthermaleng.2009.10.004.

17. Klein S.A. An Explanation for Observed Compression Ratios in Internal Combustion Engines. Journal of Engineering for Gas Turbine and Power, 113(4), 1991, 511-513. DOI: 10.1115/1.2906270.

18. Li Y., Li H., Guo H., Li Y., Yao M. 2017. A numerical investigation on methane combustion and emissions from a natural gas-diesel dual fuel engine using CFD model. Applied Energy, 205, 2017, 153-162. DOI: 10.1016/j.apenergy.2017.07.071.

19. Lu X., Zhang F., Liu Y., Wang S. Analysis on Influences of Scavenging Ports Width to Scavenging Process Based on Opposed Piston Two Stroke Diesel Engine. Energy Procedia, 158, 2019, 58385843. DOI: 10.1016/j.egypro.2019.01.543.
20. Martyn R. Benefits and Challenges of Variable Compression Ratio (VCR). SAE Technical Paper, 2003, 003-01-0398. DOI: 10.4271/2003-01-0398.

21. Mattarelli E., Cantore G., Rinaldini C. A., Savioli T. Combustion System Development of an Opposed Piston 2-Stroke Diesel Engine. Energy Procedia 126, 2017, 1003-1010. DOI: 10.1016/j. egypro.2017.08.268.

22. McAllister C.D., Simpson T.W. Multidisciplinary robust design optimization of an internal combustion engine. Journal of Mechanical Design, 125(1), 2003, 124-130. DOI: 10.1115/1.1543978.

23. Ning L., Duan Q., Wei Y., Zhang X., Yang B., Zeng K. Experimental investigation on combustion and emissions of a two-stroke DISI engine fueled with aviation kerosene at various compression ratios. Fuel, 259, 2020, 116224. DOI: 10.1016/j.fuel.2019.116224.

24. Nowacki M., Olejniczak D. Correction of the method of assessing exhaust emission during the flight of the aircraft, including impact of changes in flight altitude on engine performance parameters. Transportation Research Procedia, 43, 2019, 3-10. DOI: 10.1016/j.trpro.2019.12.012.

25. Pastor J.V., Lopez J.J., Garcia J.M., Pastor J.M. A 1D model for the description of mixing-controlled inert diesel sprays. Fuel, 87(13-14), 2008, 28712885. DOI: 10.1016/j.fuel.2008.04.017.

26. Payri F., Benajes J., Margot X., Gil A. CFD modeling of the in-cylinder flow in direct-injection diesel engines. Computers \& Fluids, 33(8), 2004, 9951021. DOI: 10.1016/j.compfluid.2003.09.003.

27. Pirault J.P., Flint M. Opposed Piston Engines: Evolution, Use, and Future Applications. SAE International, 2010.

28. Reitz R.D., Rutland C.J. Development and Testing of Diesel-Engine CFD Models. Progress in Energy and Combustion Science, 21(2), 1995, 173-196. DOI: 10.1016/0360-1285(95)00003-Z.

29. Ryan T.W., Callahan T.J. Homogeneous Charge Compression Ignition of Diesel Fuel. SAE Technical Paper, 1996, 961160. DOI: 10.4271/961160.

30. Takeuchi K., Toyao T. Development of second generation common rail system. IMechE Conference Transactions, 2, 2003, 1-9.

31. Zhang Z., Zhang P. Cross-impingement and combustion of sprays in high-pressure chamber and opposed-piston compression ignition engine. Applied Thermal Engineering, 144, 2018, 137-146. DOI: 10.1016/j.applthermaleng.2018.08.038.

32. Zhang Z.Y., Zhang P., Zhao Z.F. Spray Impingement and Combustion in a Model Opposed-Piston Compression Ignition Engine. Combustion Science And Technology, 189(11), 2017, 1943-1965. DOI: 10.1080/00102202.2017.1340278. 